\title{
Thai Oil Massage: The Application of Traditional Knowledge in North-eastern Thailand
}

\author{
Rapeepan Sirisumpan ${ }^{1}$, Songkoon Chantachon ${ }^{1} \&$ Kosit Phaengsoi ${ }^{1}$ \\ ${ }^{1}$ The Faculty of Cultural Science, Mahasarakham University, Khamriang Sub-District, Kantarawichai District, \\ Maha Sarakham Province, Thailand \\ Correspondence: Rapeepan Sirisumpan, The Faculty of Cultural Science, Mahasarakham University, Khamriang \\ Sub-District, Kantarawichai District, Maha Sarakham Province 44150, Thailand. E-mail: \\ rsirisumpan156@hotmail.com
}

Received: June 9, 2014 Accepted: July 16, 2014 Online Published: September 22, 2014

doi:10.5539/ach.v7n1p67 URL: http://dx.doi.org/10.5539/ach.v7n1p67

\begin{abstract}
This qualitative research reviews the current state of traditional oil massage in the North-eastern region of Thailand and identifies methods to preserve traditional knowledge. The findings are obtained by interview, observation and focus group discussion. The results show that traditional knowledge of oil massage was developed to combat occupational health problems in local communities, and that it has been inherited through both self-education and apprenticeship. For each treatment, the masseur/masseuse (Maw Nam Man) prepares $\mathrm{him} /$ herself and his/her equipment. He/she then reviews the patient position before proceeding with the oil massage. There are no adverse effects during or after well-executed traditional massage therapy. In order to incorporate traditional oil massage therapy in holistic healthcare under the supervision of the Ministry of Public Health, traditional wisdom must be integrated with modern medicine procedures and a management framework must be formulated.
\end{abstract}

Keywords: traditional knowledge, oil massage, traditional masseuse, holistic healthcare

\section{Introduction}

From historical evidence, researchers believe that both Egypt and China have recorded massage for over 5,000 years, while 1,000 years later there were paintings representing massage therapy in India (Podder, 2002). These cultures influenced much of Thai society and were the foundations on which Thai massage was based. The first historical evidence of massage in Thailand was found in the stone inscriptions of King Ramkhamhaeng and has been dated to 1357. From these beginnings, the field of Thai traditional medicine progressed and expanded, especially the discipline of Thai massage in the Ayutthaya (1351-1767) and Rattanakosin (1782-1932) Kingdoms. Due to war, some knowledge and documentation disappeared, which King Rama I sought to restore upon his ascendency in 1782. Perhaps the major contribution of King Rama I to Thai massage was the restoration of the royal temple Chettuphon Wimon Mangkhlaram Ratchaworamahawihan (Wat Pho). The temple was reconstructed upon a centre of traditional Thai medicine and came to be recognised as the first public university in the country. One of the earliest traditional massage schools was established at the temple and Wat Pho is considered the home of traditional Thai medicine. King Rama I also gathered experts in traditional medical knowledge to inscribe medical texts and sculpt recreations of traditional Thai exercise postures (Ungpinitpong, 2008).

Knowledge of massage is a heritage of local Thai society. People in communities used massage techniques to relieve suffering from pain caused by occupational activities, mostly farming. This local knowledge was considered as both science and art, created by families and the simple, peaceful community culture of Thailand (Dumri, 2002). Traditional massage has been informally inherited by observation of experts and self-teaching. The benefits of massage are muscle relaxation, improved blood and lymphatic circulation, increased haemoglobin and stress relief. Nowadays, the science of Thai traditional medicine has been approved under the Practice of the Art of Healing Act BE 2542 (1999) by the Institute of Thai Traditional Medicine, Ministry of Public Health and three related laws: Nursing Act BE 2541 (1998), Drug Act BE 2510 (1967), and Wisdom of Thai Traditional Medicine Protection and Promoting Act BE 2542 (1999). However, traditional practitioners are not legally certified according to the existing system and there are no national standards, although traditional 
knowledge is controlled and supported in every community. National standardisation would mean that each community could not individually manage its own traditional knowledge (Matichon, 2002).

People in the modern global era consistently turn to advanced mainstream medical treatments. Although traditional knowledge of oil massage has so much value, this alternative treatment may disappear if its conditions and problems are ignored. The research team was thus interested in studying the traditional knowledge of oil massage in North-eastern Thailand to assess its state, identify its problems and find ways to preserve its place in local society.

\section{Methodology}

This research has two primary aims: 1) to study the state of and the problems caused by using traditional knowledge of oil massage and 2) to develop a model to apply traditional massage knowledge to the mainstream system of holistic healthcare. This is a qualitative investigation. Three provinces in the North-eastern region of Thailand were purposively selected as the research area. These were Khon Kaen, Mahasarakham and Roi Et. These provinces were selected due to their long history of traditional oil massage culture and individual treatment using traditional oil massage techniques. Purposive sampling identified 83 randomized samples for the study. The samples were divided into three groups. The first group (key informants) totalled 18 individuals: representatives from the provincial cultural office, hospital deans, village leaders and abbots. The second group (casual informants) totalled 15 individuals: Masseurs/masseuses (Maw Nam Man) from the three provinces. The final group (general informants) totalled 50 individuals: patients and their relations. Data was collected by structured (Appendix) and non-structured interviews, participant and non-participant observation and focus group discussion. After all data had been collected, it was validated using data and methodological triangulation. Data was analysed in line with the research aims using typological procedures and results are here presented as a descriptive analysis (Chantavanich, 2004). This study was conducted from October 2012 to August 2013.

\section{Results}

Traditional oil massage in the research area was developed to cure health problems of villagers in the community. The traditional knowledge was inherited by two methods: 1) self-learning through experimentation or from textbooks and 2) learning by observing and listening to the experience and advice of expert practitioners and replicating their skill. The desirable characteristics of a traditional oil masseur/masseuse are a good service mind, generosity, friendliness, honesty, patience, sense of responsibility and love of helping others. Mrs. Thongkham Paladkrong (55 years old) from Baanpai District, Khon Kaen Province said that she started to be a masseuse after self-learning from textbooks. When her family had a more secure financial status and she had more spare time, she began to practice traditional oil massage with the masseur in her village (Thongkham Paladkrong, personal communication, 2012). According to interviews with Maw Nam Man, the research team summarized and divided the traditional oil massage procedures in two steps: preparation and approach (Table 1). Mrs. Krongkaew Meelap (47 years old), a Maw Nam Man from Borabue District, Mahasarakhram Province, explained that when her patients visit her and ask to be treated she has to review patient information and perform a body pain examination. She has to prepare her massage equipment and the setting, check her uniform then meditate before starting her massage procedure (Krongkaew Meelap, personal communication, 2012). Mr. Kwanchai Singchan (56 years old) Maw Nam Man from Thawat Buri District, Roi Et Province, said he usually prepares the massage oil by himself, but sometimes purchases medicinal herb oil to apply to the painful areas before applying pressure to those areas of the body to provide relief (Kwanchai Singchan, personal communication, 2012). In addition, no patients massaged by authentic Maw Nam Man suffer from side-effects or pain after the treatment.

Table 1. Current state and problems with traditional oil massage

\begin{tabular}{|c|c|c|}
\hline \multicolumn{3}{|c|}{$\begin{array}{l}\text { Traditional oil massage in three North-eastern Thai provinces } \\
\text { Current state }\end{array}$} \\
\hline Preparation & Approach & Problems \\
\hline $\begin{array}{l}\text { Standards of operating } \\
\text { procedure are established } \\
\text { and presented to customers } \\
\text { as posters or sign-boards. } \\
\text { Facilitators are ready, both } \\
\text { physically and mentally, to } \\
\text { provide services. }\end{array}$ & $\begin{array}{l}\text { Oil massage technique and } \\
\text { method } \\
\text { - Maw Nam Man asks patient } \\
\text { general information and } \\
\text { medical history. } \\
\text { - Physical tests are done and }\end{array}$ & $\begin{array}{ll}\text { No patients receiving } \\
\text { traditional oil massage had } \\
\text { complications or adverse } \\
\text { side effects during or after } \\
\text { treatment } \\
\text { Rules of traditional oil massage }\end{array}$ \\
\hline
\end{tabular}


- The location is clean and there is adequate air and light.

- Massage equipment and tools are prepared. painful positions determined.

- Massage oil could be made by the Maw Nam Man or bought from a medical store. It is applied to pressure areas and the pressure points are felt with a slight push of the thumb before starting the massage.

Traditional knowledge of oil massage

- $\quad$ This knowledge is able to treat symptoms of pain at various points of the body, including muscle numbness and sprains.
- Do not practice massage with drunk patients or with those having recently undergone an operation (in the last 2 months).

- Maw Nam Man who are drunk or have a high fever are not allow to treat patients.

- Maw Nam Man must wash their hands before and after performing a massage.

- Some Maw Nam Man believe that having a meal at the massage location will cause the patient condition to deteriorate.

The research team collected data from the interviews and organised it to classify four dimensions of holistic healthcare processes for traditional oil massage: Physical, psychological, social and spiritual (Table 2, Figure 1). The research team then incorporated this data into a focus group discussion on August $20^{\text {th }} 2013$ to consider methods to apply the traditional knowledge of oil massage to modern holistic healthcare under the supervision of the Ministry of Public Health. Successful application would allow traditional knowledge of oil massage to continue in modern society. According to the focus group discussion, informants from three provinces, including representatives from government institutions, agreed to integrate the traditional medicine treatment processes into their modern medical care. They also agreed to put traditional oil massage knowledge into their management framework by using the 'TERMS Model for Community Self-Reliance', consisting of five categories: Technology, Economy, Resources, Mental and Socio-culture (Table 3).

Table 2. Holistic healthcare processes for traditional oil massage knowledge

\begin{tabular}{|c|c|}
\hline Dimension & Details \\
\hline Physical & $\begin{array}{l}\text { - Research or model of holistic healthcare management has to be established. } \\
\text { - Therapeutic practice must be rearranged in steps and according to } \\
\text { recommendations of a qualified physician. } \\
\text { - Patient and masseur/masseuse must be recorded. } \\
\text { Patients should follow the lifestyle changes recommended by Maw Nam Man. }\end{array}$ \\
\hline Psychological & $\begin{array}{l}\text { - The patient has to trust the Maw Nam Man and undergo a course of treatment to } \\
\text { recover fully. In addition, the Maw Nam Man must be trustworthy and } \\
\text { encourage the patient. }\end{array}$ \\
\hline Social & $\begin{array}{l}\text { - Traditional oil massage training should be arranged. } \\
\text { Medicinal herb experiments to formulate massage oil must be supported to } \\
\text { increase treatment effectiveness and variety. }\end{array}$ \\
\hline Spiritual & $\begin{array}{l}\text { - It is recommended that all patients are screened before massage to determine if } \\
\text { there are any reasons to prevent the massage treatment from taking place. } \\
\text { - } \quad \text { Psychological consultancy is necessary for traditional oil massage treatment. } \\
\text { - A patient's medical history and daily lifestyle information must be examined. } \\
\text { Patient encouragement after the massage will instil more confidence and trust in } \\
\text { the treatment. }\end{array}$ \\
\hline
\end{tabular}


Table 3. TERMS MODEL of traditional oil massage for the community

\begin{tabular}{|c|c|}
\hline Matrix & Details \\
\hline Technology & $\begin{array}{l}\text { A plan of holistic healthcare management should be researched, } \\
\text { developed and publicized. } \\
\text { Medical records of traditional oil massage patients and practitioners } \\
\text { must be kept. }\end{array}$ \\
\hline Economy & $\begin{array}{l}\text { - Public relations would increase patient confidence. } \\
\text { - Service prices and methods must be cleared prior to treatment. } \\
\text { - Medicinal herb cultivation and use should be promoted. }\end{array}$ \\
\hline Natural Resources & $\begin{array}{l}\text { Developing herbal recipes into the new, more convenient dosages, } \\
\text { forms and packaging are necessary. }\end{array}$ \\
\hline Mental & $\begin{array}{l}\text { Counselling services by Maw Nam Man or psychologist must be } \\
\text { provided for the patient alongside treatment. }\end{array}$ \\
\hline Socio-culture & $\begin{array}{l}\text { - Short ceremonies prior to treatment where the practitioner pays } \\
\text { respect to their instructor could promote Maw Nam Man confidence } \\
\text { and increase his fortunes. } \\
\text { Basic traditional oil massage techniques that are easy for patients to } \\
\text { do themselves or with family members should be taught in the } \\
\text { community. }\end{array}$ \\
\hline
\end{tabular}

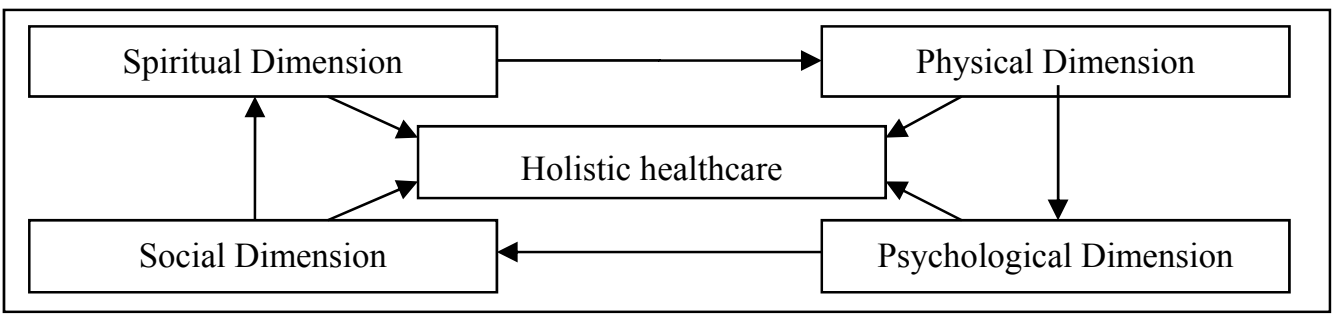

Figure 1. Holistic healthcare framework

\section{Discussion}

Traditional knowledge of oil massage was developed to help cure community health problems by both self-experimentation and learning from expert experience. This represents the symbolic concept of socialization, where both formal and informal instruction is used. The concept consists of three compositions: 1) Social interaction between at least two people, 2) language used to communicate and understand and 3) relationships between teachers and students (Sanyawiwat, 2008). In a study of traditional healers in Nan province, Panom Wongthai found that the medical skill of each healer depended on their accumulated experience in curing villager illnesses. Once they had gathered sufficient knowledge they were considered experts and were accepted by the community (Wongthai, 2004).

Current oil massage procedures begin with the preparation of services and facilities, then treatment starts using the individual techniques of the Maw Nam Man. The preparation is a symbolic step to instil confidence in the patient and to reveal the expertise of the masseur/masseuse. Somphong Dulyakit explained that people use symbols to communicate or explain their level of understanding and experience. Even if that experience is not immediately apparent, patients are able to interpret the symbols displayed during the preparation stage and follow the conditions given by those symbols (Dulyanukit, 2006).

The important things that Maw Nam Man have to do are analyse and understand the pros and cons of each pattern of traditional oil massage for more effective treatment. The Maw Nam Man should clearly describe the details of massage approaches to their patients, be organised and serve their position honourably. This situation is a representation of the structural functional theory. People have basic needs for being accepted in their society: physical needs, mental needs, symbolic needs and the responses of other members of society (Santasombat, 2005). In their study of family practice residents and family physicians regarding complementary and alternative medicine, Frenkel, Ben-Arye and Hermoni (2004) found that alternative medicine is well known in the West. 
Education could change trainee attitudes regarding participation of family healthcare. Knowledge of alternative medicine can be developed as a strategic model for healthcare and the environment.

Further research must focus on the comparison of traditional oil massage in different ethnic groups or countries in order to identify outstanding or unique features to benefit the general development of traditional knowledge in the field. Further study must also consider the problems with and threats to traditional oil massage knowledge inheritance and ways to support more systematic and secure heritage. It is also recommended to establish an effective massage procedure in holistic healthcare as a study program.

\section{Conclusion}

The local knowledge of traditional oil massage can be applied as a holistic healthcare treatment. The traditional skill and modern medicine can be developed simultaneously to professionalise traditional Thai medicine.

\section{References}

Chantavanich, S. (2004). Qualitative research methodology (14th ed.) [in Thai]. Bangkok: Dansutha Printing.

Dulyanukit, S. (2006). Sociology and development [in Thai]. Bangkok: Odeon Store.

Dumri, P. (2002). The study of Mo Sen: North-eastern traditional massage [in Thai]. PhD Thesis. Mahasarakham University, Mahasarakham, Thailand.

Frenkel, M., Ben-Arye, E., \& Hermoni, D. (2004). An approach to educating family practice residents and family physicians about complementary and alternative medicine. Complementary Therapies in Medicine, 12(2), 118-125. http://dx.doi.org/10.1016/j.ctim.2004.07.044

Matichon. (2002), Thai traditional medicine: folk doctors in the National Health Act [in Thai]. Newspaper, 8th August, 2002.

Podder, T. (2002). The Magic of Massage. Delhi: Pustak Mahal.

Santasombat, Y. (2005). Humans and culture (3rd ed.) [in Thai]. Bangkok: Chulalongkorn University Press.

Sanyawiwat, S. (2008). Sociological theories: Context and basic methodology (2nd ed.) [in Thai]. Bangkok: Chulalongkorn University.

Ungpinitpong, W. (2008). Thai massage therapy [in Thai]. Bangkok: Suwiriyasan.

Wongthai, P. (2004). Folk healer existence: Case study in Nan province [in Thai]. PhD thesis. Thammasat University, Bangkok, Thailand. 


\section{Appendix}

\section{Structured interview}

Thai oil massage: The application of traditional knowledge in North-eastern Thailand

\section{Instructions}

1. This interview is used for casual informants: Maw Nam Man

2. This interview has four parts

- Part 1 - Personal information

- Part 2 - Research aims

- Part 3 - Ritual element and procedure of patient treatment

- Part 4 - Application of traditional knowledge in holistic healthcare

\section{Part 1: Personal information}

First name (Mr/Miss/Mrs). Last name Age. ...ob.

Marital status.

Highest education level

Permanent address

Province

Correspondence address

Province

Treatment experience

\section{Part 2: Research aims}

Background of traditional oil massage knowledge

...The conditions and problems of using traditional oil massage knowledge in holistic healthcare, related to ceremonies, traditions and natural resources in the community

Preparation

Treatment procedure

......After the treatment

Local knowledge application in holistic healthcare

Traditional knowledge usage

.....

Modern knowledge usage 
$\cdots$

...Traditional knowledge applied with modern knowledge in holistic healthcare

\section{Part 3: Ritual element and procedure of patient treatment}

What type of oil do you formulate and use in traditional oil massage?

Do you conduct any ceremony or incantation before massage oil formulation?

What tools or equipment do you use in ceremonies or incantations?

$\cdots$

What type of patient usually comes for traditional oil massage?

-

How do you diagnose them?

...

What tools or equipment do you use for diagnosis?

$\cdots$

What type of disease do you usually treat?

$\cdots$

Which part of the body do you treat most?

$\cdots$

Do you consider dispensing herbal or modern medicines? If yes, what are they?

$\cdots$

How long does one treatment take?

...

Where do you provide traditional oil massage?

$\cdots$

How much will the patient have to pay? 
Part 4: Application of traditional knowledge in holistic healthcare

...

$\cdots$

$\cdots$

Other suggestions

$\cdots$

$\cdots$

Date ....

\section{Copyrights}

Copyright for this article is retained by the author(s), with first publication rights granted to the journal.

This is an open-access article distributed under the terms and conditions of the Creative Commons Attribution license (http://creativecommons.org/licenses/by/3.0/). 